\title{
Acceptance and Inclusivity: An Islamic Artforms Perspective
}

Consoler Teboh' ${ }^{*}$, Ph.D., Sylvester Amara Lamin², Ph.D. and Ed.D.

${ }^{1 *}$ Associate Professor, Social Work Department, Saint Cloud State University, United States.

${ }^{2}$ College of Social Work, The Ohio State University, Columbus Ohio, United States.

\author{
Article Details \\ Article Type: Research Article \\ Received date: $01^{\text {st }}$ December, 2019 \\ Accepted date: $22^{\text {nd }}$ January, 2020 \\ Published date: $29^{\text {th }}$ January, 2020
}

*Corresponding Author: Consoler Teboh, Associate Professor, Social Work Department, Saint Cloud State University, United States. E-mail: cteboh@stcloudstate.edu

Citation: Teboh, C., \& Lamin, A. L. (2020). Acceptance and Inclusivity: An Islamic Artforms Perspective. J Ment Health Soc Behav 2(1):109. https://doi.org/10.33790/jmhsb1100109

Copyright: (C2020, This is an open-access article distributed under the terms of the Creative Commons Attribution License 4.0, which permits unrestricted use, distribution, and reproduction in any medium, provided the original author and source are credited.

\section{Abstracts}

This research explored the implication of Islamic Art forms as a way of understanding the significance and hence change the stereotypes in a community. Islamic art is an umbrella term that has been used since the later end of the 7th century. It embraces all forms architectural decoration, textile design, wood and ivory carvings, songs and music. Thus when people move to new places they take along their culture and understanding the culture of Muslims through Islamic Art form forms is the basis of this study. The question that "would understanding Islamic art forms influence people's perceptions" frames the primary objective of the essay. This cannot be achieved without revisiting some of the determinants, examples and consequences of Islamophobia.

\section{Historical overview of religious freedom}

The idea that the United States has always been a bastion of religious freedom is reassuring. However, this view is utterly at odds with the historical record of the country. Feelings of animosity directed towards certain identified religious groups are, therefore not new [1]. There have been hostilities between the following: Protestant and native beliefs, Protestants and Catholics, Christians, and Jews and very recently, Christians and Muslims [2]. This 'last' trend of hostility is ongoing, hardening, and on the rise. This rise is within the backdrop of the fact that Muslim history in the United States dates back to the early days of the country's establishment. Documentation and personal communications verify that as early as the 1600 s some of the slaves who were sold to the United States were Muslims [3]. The Islamic Resource Group's oral history project confirms information regarding early settlement [4]. Interestingly and conversely to the time of the early settlement of Muslims in the United States, the relationship between them and Christians has instead gone sour. In fact, this phobia has hardened within the fabric of society including law enforcement [5].

The human difference which particularly leads to hate is better understood as the extreme form of discrimination [2]. Such hate comes from a culture of segregation, discrimination and marginalization of people we assume to be 'different'. Within modern society, power hierarchies constitute dominance over 'difference' [6]. The difference thus constructs intersecting social hierarchies pertaining to gender, race and spirituality; amongst others. People including members of the law enforcement corps gravitate to those they see as having the same characteristics as they [6]. Conversely, they direct animosity toward those who are/or have different affinities [5]. No wonder that with the growing number of immigrants particularly from mostly Islamic countries in the United States, there is bound to be tensions.
In Minnesota which currently boasts of more than 150,000 Muslim immigrants [7] for instance, it was no surprise that a five-year veteran of the Rochester Police Department reposted the following statement on his Facebook page: "Studies have shown that Muslim Radicals are a lot less prone to violence after they've been shot in the (F-word) face." [8].

Several other reasons have led to rising tensions and outright hate crimes. For years in the Twin Cities of Minnesota, residents who identify as members of the Islamic community say they have had their bank accounts closed unnecessarily and without reason by some Minneapolis-based Financial Corporations [9]. This, and several other cases in the country particularly following the Muslim ban has made the rising tensions and animosity against each other to reach a breaking point. The recent killings of Muslims and Jews in the country seem to be microcosms of the underlying hate that has laden the fabric of our society. On the individual level, $69 \%$ of Muslim women who wear a hijab have reported discrimination versus $29 \%$ of Muslim women who do not wear a hijab [10]. From the political and judicial points of view, things are not different. Ordinance 389.05 of the City of Minneapolis [11] states that:

"There have come into being within the city certain loud, avoidable, unnatural and unnecessary noises, which under certain circumstances and conditions, constitute a serious threat to the health, the welfare, the contentment and the feeling of well-being of our people, p.1"

This document out-rightly bans the "Muslim call for prayers" in certain parts of the city. Whereas in Stearns county Minnesota, Muslims have been ordered to strip their hijabs in order to take photographs for their driver's licenses and those that were incarcerated were also asked to strip their head covers off. Interestingly, no other groups of persons have been put under such circumstances in absolute violation of these people's religious beliefs.

\section{Review of Literature}

Many people understand that freedom of religion means the ability to practice one's faith by choice openly or privately and to be free of intimidation or violence [12]. However, designated holy spaces for the purpose of religious allegiance particularly the, Mosque or Synagogue in the United States have not had the same share of reverence that is usually accorded toChristian holy places [7]. In fact, their premises have been desecrated and their members injured and sometimes killed $[3,13]$. The focus of on this section is placed on the fact that the aftermath of $9 / 11$ has induced negative attitudes towards Muslims whom most people tend to strongly associate with any act of terrorism $[5,14,15]$. 
All forms of media have played a colossal role in developing such negative association as it constantly portrays Muslim people in violent terrorist acts $[9,12]$. Whereas these two factors have been identified as the driving forces of the divide, the definition, causes and consequences of Islamophobia are reviewed.

\section{Definition of Islamophobia}

Islamophobia is said to be an exaggerated fear, hatred, and hostility toward Islam and Muslims [16]. It is perpetuated by negative stereotypes resulting in bias, discrimination, marginalization and violence [16]. The term Islamophobia most likely evolved out of the "grassroots situation being faced by Muslims in the London Borough of Brent in the early 1980s" [13] Contrary to this claim, University of California-Berkeley Center for Race and Gender assumes they coined the word and posit that:

"Islamophobia is a contrived fear or prejudice fomented by the existing Eurocentric and Orientalist global power structure. It is directed at a perceived or real Muslim threat through the maintenance and extension of existing disparities in economic, political, social and cultural relations, while rationalizing the necessity to deploy violence as a tool to achieve "civilizational rehab" of the target communities (Muslim or otherwise). Islamophobia reintroduces and reaffirms a global racial structure through which resource distribution disparities are maintained and extended, para.1" [17].

The very definition of the word Islamophobia connotes to the hurting and exclusion of Muslims and to a lesser extend Muslimlook-alikes such as the Sikh from social, political, and civic life. Causes of Islamophobia.

Pappas [18] identified several factors that stem from the strong role of the media. He posited that fear mongering, human differences and distrust have led to the continued causes of hate of Muslims [18]. According to the Muslim Youth Foundation [19] the biggest misconception about Islam, no doubt results from the constant stereotyping and bashing the media gives Islam. When a gunman attacks a mosque in the name of Judaism, a Catholic IRA guerrilla sets off a bomb in an urban area, or Serbian Orthodox militiamen rape and kill innocent Muslim civilians, these acts are not used to stereotype their faith as a whole.This results in misunderstanding of Muslims, lack of awareness of what Islam actually stands for, and widespread mis-information. In fact, when anything is repeated frequently in the media and unfortunately, by Christian leaders, it leads to Muslim groups constantly being associated with extreme views of violence and terrorism.

The role of politicians cannot be overstated. Research suggests that extreme political rhetoric can contribute to a spike in hate crimes. Woolfe, [20] posits that one of the strongest predictors of whether people hold unfavorable views of Muslims is whether they adhere to the political rhetoric of the time. Islam is widely construed as the intrinsic negative 'Other' engendering responses of general concern, diffuse anxiety, and in increasing instances palpable fear [21]. Many American politicians therefore take it upon themselves to seek political sympathy from their base by increasing the 'Other' rhetoric. The current United States president makes excessive use of this propaganda for his personal gains. The recent elected representative from the state of Minnesota - Ilhan Omar has seen her own share of attacks. "Omar dared to challenge the way supporters of Israel have worked to silence debate on US policy toward the IsraeliPalestinian conflict, she became a victim of incitement, and the target of legislation meant to shame her." This depiction only goes to show that it is not only the ordinary Muslim that is being assaulted by politicians but even those in power.

\section{Consequences of Islamophobia}

From shouts on the street to "go back where you came from," to shallow arguments about the threat of Islam advanced by so-called experts and elected officials, Islamophobia has influenced the public discourse surrounding Muslims across all levels of society [22]. However, "beyond hurtful rhetoric by ill-wishing passersby, those frequenting anti-Muslim online forums, and political representatives, the effect of Islamophobia is having a much darker impact on Muslim communities ranging from misguided policies to outright acts of violence against Muslims and their houses of worship, p.4" [23].

Other identified consequences of Islamophobia include the high price that governments are paying to combat Anti-terrorism. According to a recent study, the U.S. has spent as much as $\$ 2.8$ trillion on the fight against terrorism since the Sept. 11, 2001 [24]. The study continues to state that the United States is going in the wrong direction and that the amount of money being spent far outweigh the actual threat. Other significant and yet non-direct financial penalties of Islamophobia are tightened Immigration policies and security laws, physical abuses and material attacks, erosion of multicultural ideals, isolation and exclusion, racial profiling, recent restrain and ban of people from predominantly Muslim countries [22]. Woofle [20] actually captures this trend and the wrong direction the United States is going in the following statement: "as long as we fail to distinguish the difference between Christianity and Christendom or between Islam and Islamdom, or between Judaism and Jews, the chances of civilization surviving on earth for as long as eighty years is distinctly problematic, p.55."

\section{Theoretical Framework}

Social change may be defined as a new fashion or mode, either modifying or replacing the old, in the life of a people, or in the operation of a society [25]. The word "change" denotes a difference in anything observed over some time [26]. Social change, therefore, would mean observable differences in any social phenomena over any period. While social change occurs in all societies, its speed or rate of occurrence is not uniform in every society [25]. In most societies, it occurs so slowly that it is often not noticed by those who live in them. Even in modern societies, there seems to be little or no change in many areas [26]. Theory of Change, as used in this context, argues that socially constructed concepts like race and hate are learned behaviors that can be treatable and curable [27]. The antidote must embody both science and education in order to transform unhealthy thinking and aid in the change process. This model assumes six steps for such change to be achieved: identification, acknowledgment, assessment, treatment, evaluation, and sustainment [25]. In order to effect change among individuals in society, these researchers argue that if people are intentionally exposed to new and different things, there is the likelihood that their attitudes, behaviors and knowledge of those things they are exposed to will improve.

\section{Methodology}

This is a pre and post mixed -method evaluation of the Association of Performing Arts Professionals (APAP) Building Bridges Midnimo Program that was implemented in St. Cloud, Minnesota. During this program the researchers assessed 22 social work students for an entire academic year. The study entailed taking a baseline of the attitudes, behaviors, and knowledge of these 22 select students [10 from the social work undergraduate second -year class (cohort 1), 6 from the social work foundation graduate program (cohort 2), and 6 from the first year social work undergraduate program (cohort 3)] toward Islam and Muslims prior to the evaluation.

Data were collected through pre and post questionnaires, embedded assignments requiring feedback, responses to questions (not featured in the surveys) but asked after events. (Hard-to read sentence) Feedback from students on these events was also collected and excerpts from most of what they said used in this final report. Note that Ahmed's presentation and Nayiz's video streaming were solely informational and students who attended these two events were not required to document anything. However, in some of the narratives and responses of a few of these students captured what they learned 
from Ahmed's presentation and Nayiz's video streaming.

The specific methods used for the documentation were as follows; through embedded assignments collected through D2L, hard copies or electronic mail, reviews or feedback from events and/or activities that students participated in either through D2L, hard copies or electronic mail, and lastly through the pre and post surveys collected through hard copies.

\section{Research Findings}

This section discusses the research findings regarding the objectives of the project. The construction of the analysis will be based on the overarching questions; namely: will the attitudes, behaviors, and knowledge of millennials aged 18-24 change positively toward Somali Muslims when they are exposed to their art and music? A mixed- methods analysis will be used to present information in this section. This means that basic quantitative analysis, such as demographic information, tables and frequency counts where applicable; as well as qualitative analysis such as direct quotes and excerpts where applicable, for each of the three cohorts will be used for the analysis. The focus however will be to determine if the objectives of the research project were met.

\section{A. Cohort One Analysis:}

\section{i. Cohort One Demographics:}

There were 10 students in $\mathrm{C} 1$ with an average age of 21.1 years. Of these 10 students 1 was a male, 9 female and no other gender identity was reported. The racial/ethnic composition was as follows: 2 students reported as African American, 1 as Hispanic or Latino, 1 as Middle Eastern/Southwest Asian, 1 as Native American or Alaskan Native, and 4 stated that they were Caucasians while 1 was
African. As per their enrollment, all of the students in the cohort were full time- second year students in the department of social work and based on their major they were all pursuing a professional degree. In terms of their cultural ties, 7 stated that they had no family connections outside the US;none had connections to one or more Muslim majority countries and 3 specified that they had family connections outside the US, but not Muslim majority countries. In terms of the importance of religion in their lives, 5 students in $\mathrm{C} 1$ stated that it is very important; 1 said it was somewhat important; 1 indicated that it was not too important and 3 reported that it was not at all important. With regards to religious affiliation 5 presented as Christians, 1 as an Hindu, 1 as unaffiliated, and 3 respondents did not respond. The breakdown of the activities for $\mathrm{C} 1$ members was as follows: 8 students attended or participated in 3 to 5 activities or programs while 2 attended 5 or more events. In terms of the political views on social issues of students in $\mathrm{C} 1$, all 10 respondents did not provide any response and/or data were not available. Whereas when it came to performing arts attendance, 1 student stated that she is likely to attend less than once a year, 8 students confirmed that they would attend 1 or 2 times a year, while 1 stated that he could attend 3 to 10 shows in a year.

\section{ii. Cohort One Attitudes:}

The pre and post-immersion survey specifically asked a question to the participants regarding their attitudes towards Somali Muslims before and after participating in all their select activities namely; performance(s), (workshop(s), Somali pamphlet review, embedded class assignments, video clip(s), Somali food experience (s), Somali students' night, and shop visit(s); amongst other activities.

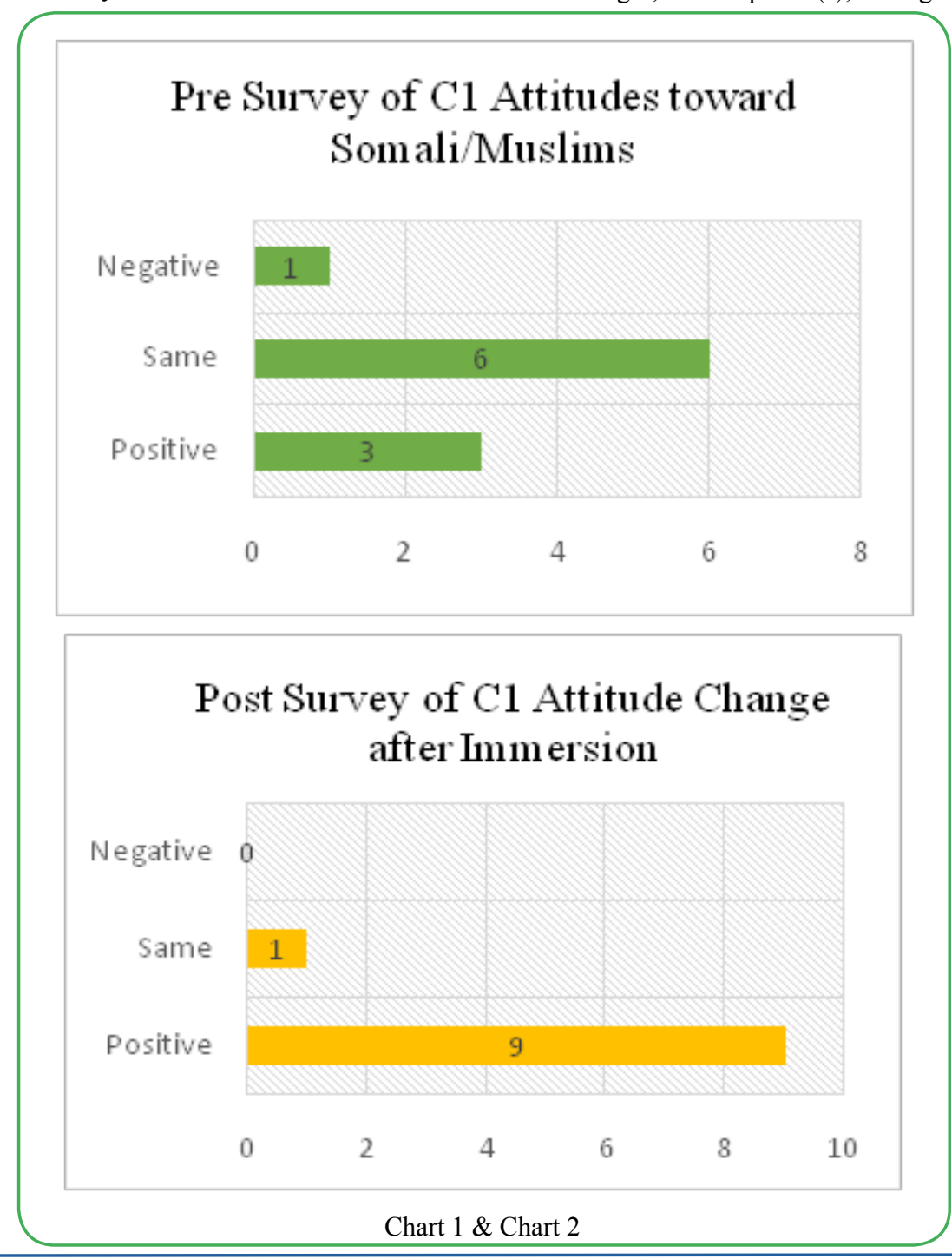


The charts 1 and 2 above compared the pre and post responses provided by $\mathrm{C} 1$ students to the question: what is your attitude towards Muslims/Somalis? Note that in the pre-survey only 3 respondents had a positive outlook about Somali/Muslims whereas that number climbed to 9 after the immersion program. In addition to the direct responses provided by $\mathrm{C} 1$ participants, they were asked why and how their attitudes have changed. To this end, they stated the following thoughts that reinforced their attitude change:

"I have a better understanding of these individuals and no longer hold many misconceptions"

"Activities like this help me challenge the biases and misconceptions that I hold"

"I can now critically examine my own views and teachings than dwell on misconceptions about others"

\section{iii. Cohort One Behaviors}

The post-immersion survey specifically asked a question to the participants regarding their behaviors towards Somali Muslims after participating in all their select activities: performance(s), (workshop(s), Somali pamphlet review, embedded class assignments, video clip(s), Somali food experience (s), Somali students' night, and shop visit(s); and other events. The responses provided by $\mathrm{C} 1$ students to the question: "what misconceptions if any about Muslims/ Somalis did you have that these activities have helped to reduce or erase and how these have changed your behavior towards them?" were used to determine if there were any behavior changes. With regards to misconceptions about Muslims/Somalis the following statements stood out:

"I thought all of them are unapproachable and unfriendly"

"I thought they are not hard workers and often have things handed to them through welfare services"

\section{"I thought that Muslims are all the same (monolithic)"}

The second potion of the question of future behavior change of $\mathrm{C} 1$ members toward Muslims/Somalis after their exposure to the aforementioned activities and programscan be grouped along the following themes (goodness and spirituality) as depicted in the excerpts below:

"Muslims/Somalis are very diverse and are good people"

"Just like Christians, spirituality is very important to Somali Muslims"

"These activities helped me erase my news-influenced misconception about Somali/Muslims"

(This needs to be revised as it has too many non-content words may indicate wordiness)

"Will miss how great the food tastes"

"I learned their value of compassion and togetherness"

"I learned about their through music, song and dance"

"Similar foods and dress with my culture (I am SE Asian)"

\section{iv. Cohort One Knowledge:}

In a bid to determine the understanding base of $\mathrm{C} 1$ participants on basic tenets such as knowledge of the Somali peoples and cultures, length of stay in the US, origin \& spirituality, impression of their art and music, exposure to food amongst other things; a 9 question survey was filled at the beginning and at the end of the research. The results of this pre and post survey were used to show that $\mathrm{C} 1$ participants had actually acquired some basic knowledge about Somali Muslims living in central Minnesota. The pre and post charts displayed below show the relative change in knowledge among $\mathrm{C} 1$ respondents before and after the research project.

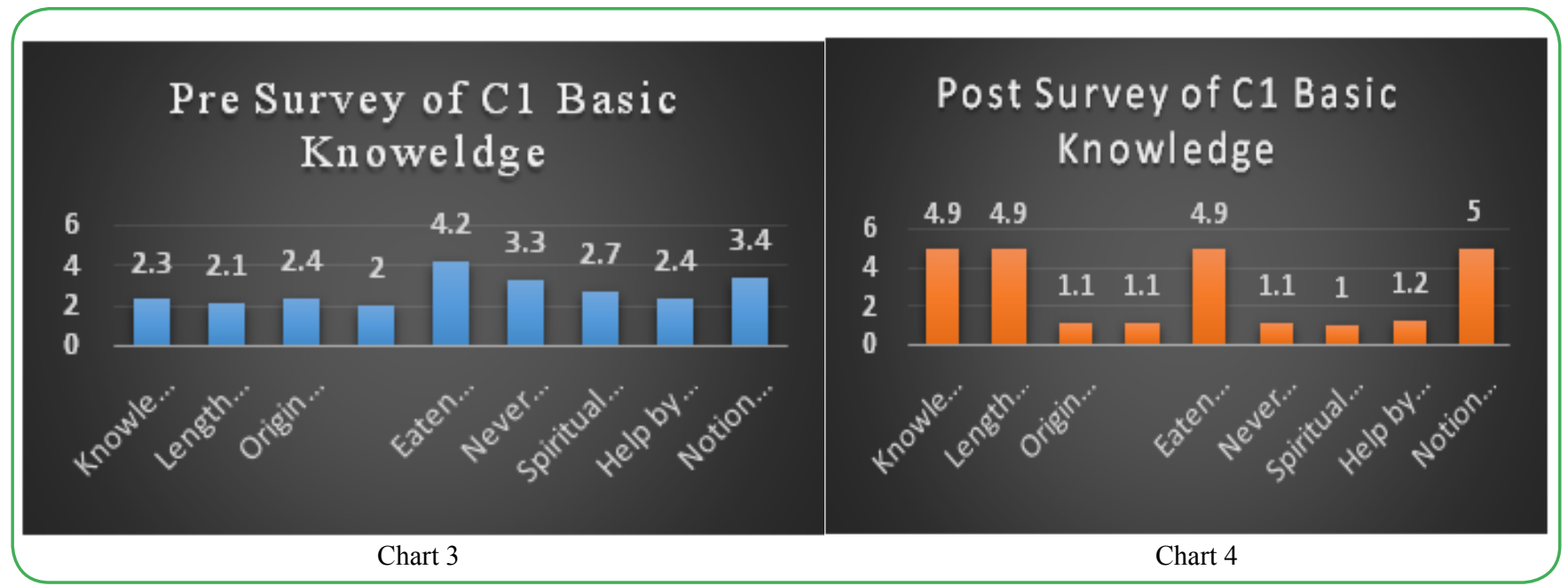

Note that in charts 3 and 4 above, questions in the affirmative have increased scores and questions in the negative have reduced scores in the post survey responses than in the pre survey responses. These changes are indicative that $\mathrm{C} 1$ participants had gained more knowledge about Somali peoples and cultures, length of stay in the US, origin \& spirituality, impression of their art and music, exposure to food amongst other things; over the course of the research project. See appendix 8 for a full review of the questions asked.

\section{B. Cohort Two Analysis:}

\section{i. Cohort Two Demographics:}

There were 6 students in $\mathrm{C} 2$ with an average age of 23.3 years. Of these 6 students none of them was a male and no other gender identity was reported. The racial/ethnic composition was as follows: 1 student reported as African American, 4 Caucasians and 1 as African. As per their enrollment, all of the students in the cohort were full time foundation students in the department of social work and based on their major, they were all pursuing a professional degree. In terms of their cultural ties, 5 stated that they had no family connections outside the US, none had connections to one or more Muslim majority countries and 1 specified that she had family connections outside the US, but not Muslim majority countries. In terms of importance of religion in their lives, 3 students in $\mathrm{C} 2$ stated that it is very important, 1 said it was somewhat important, one stated that it was not too important and 1 indicated that it was not at all important. With regards to religious affiliation 3 presented as Christians, 1 reported as "don't know or decline to state", and 2 respondents did not provide any response. The breakdown of the attendance for $\mathrm{C} 2$ members was as follows: 4 students attended 3 to 5 activities or programs while 2 attended 5 or more events. In terms of the political views on social issues of students in $\mathrm{C} 2$, all 6 respondents did not provide any response and/or data were not available. However,when it came to performing arts attendance, 2 students stated that they will most likely attend less than once a year 
and 4 students confirmed that they would attend 1 or 2 events in a year.

\section{ii. Cohort Two Attitudes:}

The pre and post-immersion survey specifically asked a question to the participants regarding their attitudes towards Somali Muslims before and after participating in all their select activities namely; performance(s), (workshop(s), Somali pamphlet review, embedded class assignments, video clip(s), Somali food experience (s), Somali students' night, and shop visit(s); in addition to other programs.

\section{Pre Survey of C2 Attitude toward Somali/Muslims}

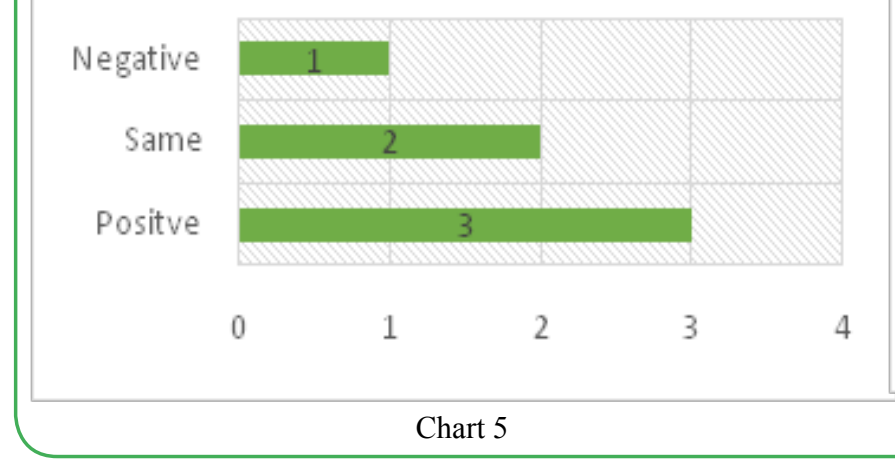

Charts 5 and 6 above compared the pre and post responses provided by $\mathrm{C} 2$ students to the question: what is your attitude towards Muslims/Somalis? Note that in the pre-survey only 3 respondents had a positive viewpoint about Somali/Muslims whereas that number scaled to 6after the immersion program. In addition to the direct responses provided by $\mathrm{C} 2$ participants, they were asked why and how their attitudes have changed. To this end, they stated the following thoughts that reinforced their attitude change:

"I feel my attitude has changed for the better; it changed after I became friends with a Somali gentleman through this program"

"My attitude has changed by hearing stories of Somali students; unlike what I was hearing in the media"

"I especially enjoyed these activities because they portrayed Muslim and Somali people as very normal people"

\section{iii. Cohort Two Behaviors:}

The post-immersion survey explicitly asked a question to the participants regarding their behaviors towards Somali Muslims after participating in all their select activities: performance(s), (workshop(s), Somali pamphlet review, embedded class assignments, video clip(s), Somali food experience (s), Somali students' night, and shop visit(s); amongst other programs. The excerpts provided by $\mathrm{C} 2$ students to the question: "what misconceptions if any about Muslims/ Somalis did you have that these activities have helped to reduce or erase and how these have changed your behavior towards them?" were used to determine if there were any behavior changes. With regards to misconceptions about Muslims/Somalis the following statements stood out:

"I just didn't know anything much about Somalis and I didn't care to find out"

"Once I believed that Muslims were quiet and had poor social skills, this research has debunked these misconceptions"

"I had the perception that Somali women are often oppressed, shy and reserved"

The second potion of the question sought to find out if future behavior of $\mathrm{C} 2$ members toward Muslims/Somalis would change after their exposure to the aforementioned activities and programs. The following themes (breakdown of ethnocentrism and mindset change) were derived from the excerpts that $\mathrm{C} 2$ participants provided below:

"I think we, myself included have an ethnocentric view of our own

\section{Post Survey of C2 Attitude Change after Immersion}

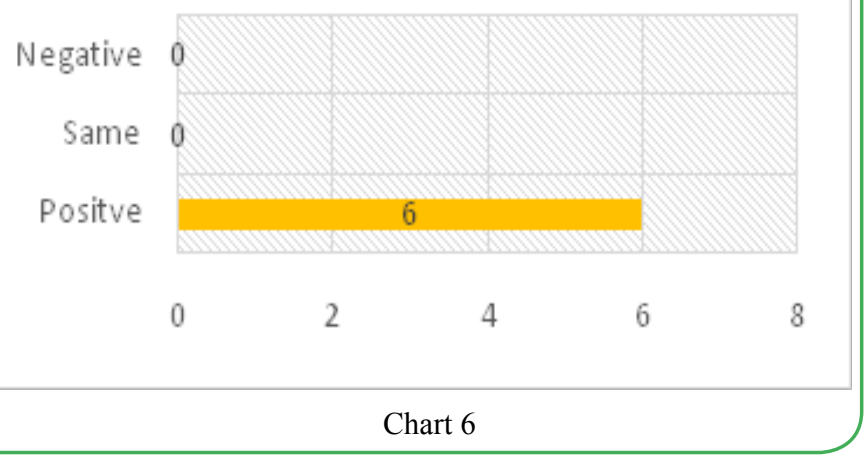

culture and exposing myself to these types of activities helps break down that mentality"

"I had the preconception that Somali culture is different simply due to my lack of exposures/experiences. I enjoyed learning about the history and culture of Somali Americans"

"I had thought they were bad/wicked people but the activities helped to change my mindset"

Another disposition that sheds some more light on the change of future behavior for members of $\mathrm{C} 2$ was rooted in the question: in what ways, if any, did these events reinforce or change the way you think about your community? The responses tended to have the following themes (community support and advocacy) as seen in the quotes below:

"The events changed the way I think about my community by showing me that community stakeholders should be in support of the Somali population and advocate for them much more than they are currently doing"

"These events showed me that if we look closely, people in our community are actually not too different, they are just varied"

"This research project has helped me to learn more about Somali people, their culture, what challenges they face, why and how they live within our community"

\section{iv. Cohort Two Knowledge:}

In order to determine the level of understanding of C2 participants on basic views such as knowledge of the Somali peoples and cultures, length of stay in the US, origin \& spirituality, impression of their art and music, exposure to food amongst other things; a 9 question survey was filled at the beginning and at the end of the research. The results of this pre and post -survey were used to show how C2 participants hadacquired some basic knowledge about Somali Muslims living in central Minnesota. The pre and post charts displayed below show the relative change in knowledge among $\mathrm{C} 2$ respondents before and after the research project.

Note that in charts 7 and 8 above, questions in the affirmative have increased scores and questions in the negative have reduced scores in the post survey responses than in the pre survey responses. These changes are indicative that $\mathrm{C} 2$ participants have gained more about knowledge about Somali peoples and cultures, length of stay in the US, origin \& spirituality, impression of their art and music, exposure to food amongst other things; over the course of the research project. See appendix 8 for a full review of the questions asked. 


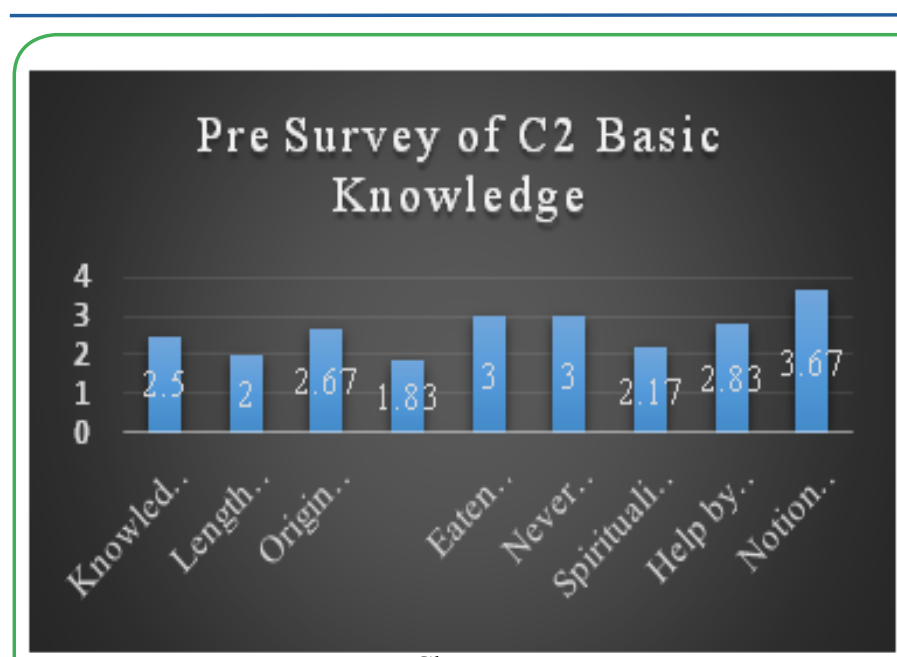

Chart 7

\section{Cohort Three Analysis:}

\section{i. Cohort Three Demographics:}

There were 6 students in $\mathrm{C} 3$ with an average age of 21 years. Of these 6 students 1 was a male, 5 female and no other gender identity was reported. The racial/ethnic composition was as follows: 1 students reported as African American, 1 as Hispanic or Latino, 1 as Middle Eastern/Southwest Asian, 1 as Native American or Alaskan Native, and 2 as Caucasians. As per their enrollment, all of the students in the cohort were full time first year students in the department of social work and based on their major they were all pursuing a professional degree. In terms of their cultural ties, 5 of the students in this cohort stated that they had no family connections outside the US while 1 stated that she had family connections outside the US, but not in a Muslim majority country. In terms of importance of religion in their lives, 3 students in C 3 stated that it is very important; 1 said it was somewhat important and 2 reported that it was not at all important. With regards to religious affiliation 4 presented as Christians, 1 as

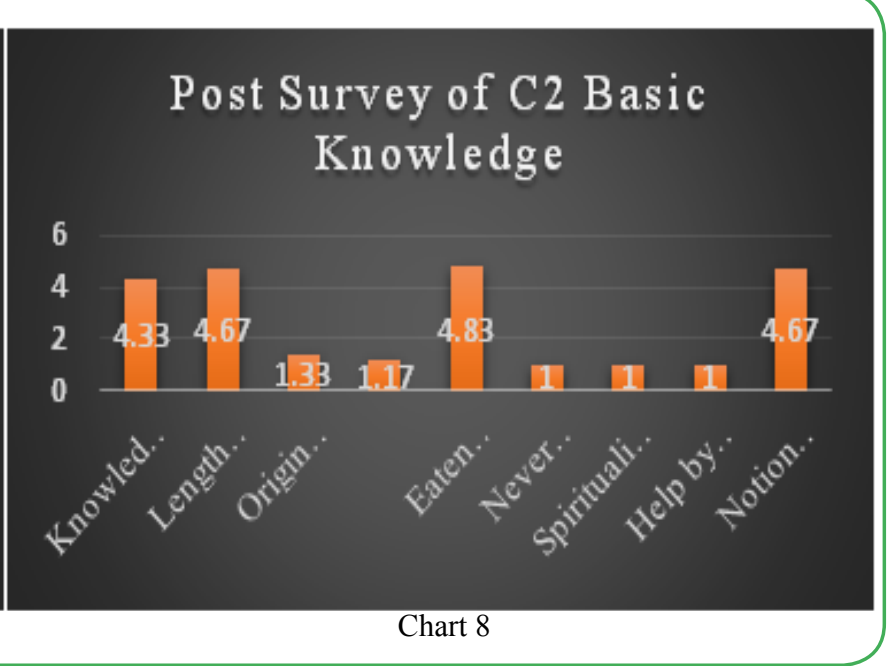

Hindu, and 1 as unaffiliated. The breakdown of the attendance for C3 members was as follows: 3 students attended 3 to 5 activities or programs while 2 attended 5 or more events. As per the political views on social issues of students in $\mathrm{C} 3$, all 6 respondents did not provide any response and/or data were not available. Though when it came to performing arts attendance, 3 students stated that they could attend less than one show in a year, 1 student confirmed that she would attend 1 to 2 events in one year, while 2 students stated that they would be able to attend 3 to 10 shows in a year.

\section{ii. Cohort Three Attitudes}

The pre and post-immersion survey specifically asked a question to the participants regarding their attitudes towards Somali Muslims before and after participating in all their select activities namely; performance(s), (workshop(s), Somali pamphlet review, embedded class assignments, video clip(s), Somali food experience (s), Somali students' night, and shop visit(s); amongst other events.

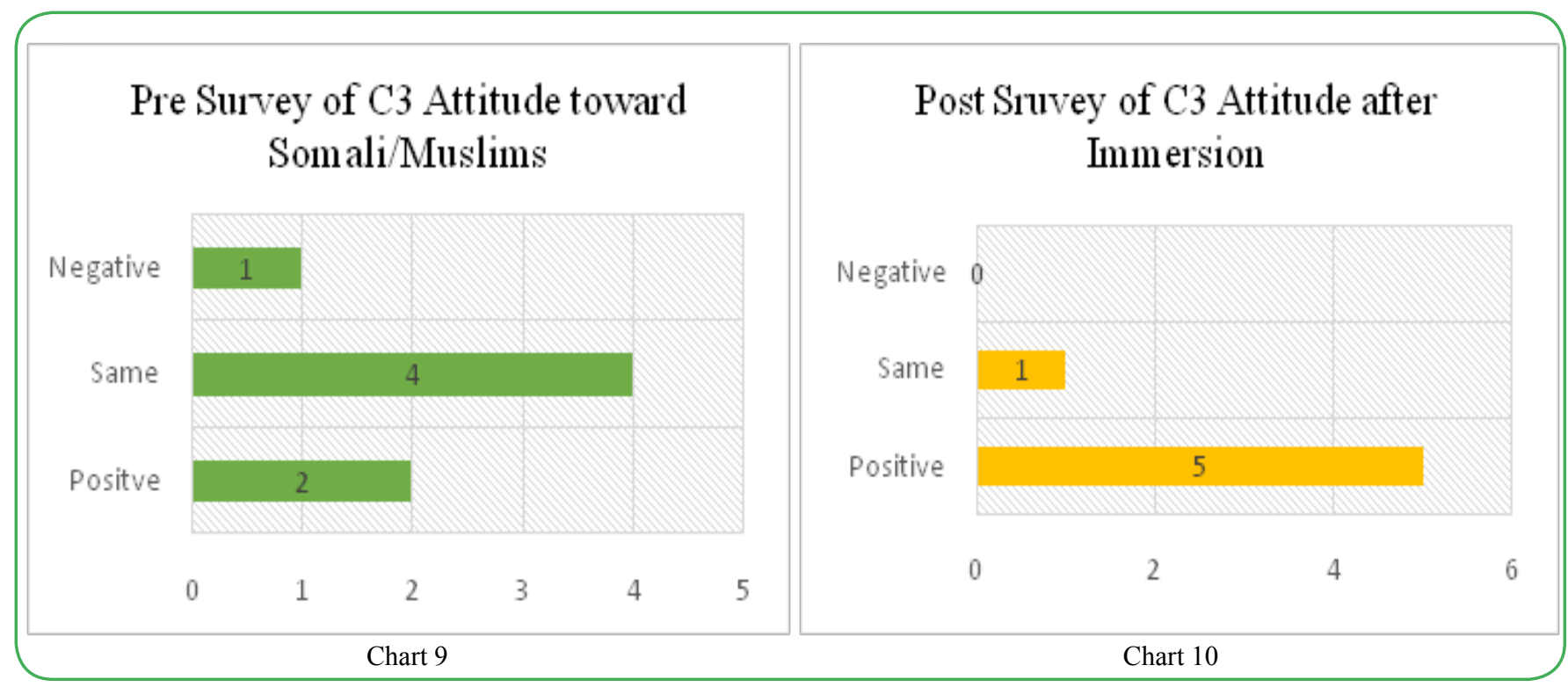

Charts 9 and 10 above compared the pre and post responses provided by $\mathrm{C} 3$ students to the question: what is your attitude towards Muslims/Somalis? Note that in the pre-survey only 2 respondents had a positive stance about Somali/Muslims whereas that number increased to 5after the immersion program. In addition to the direct responses provided by $\mathrm{C} 3$ participants, they were asked why and how their attitudes have changed. To this end, they stated the following thoughts that reinforced their attitude change:

"My preconceptions have changed positively"

"I have never believed the misconceptions I have heard because I want to believe all people are good"

"If anything, I think Muslims and/or Somalis sometimes work harder than people born in America because they want to be here"

"Just because there have been terrorists who are Muslim does not mean that every Muslims and/or Somalis is a terrorist"

\section{iii. Cohort Three Behaviors}

The post-immersion survey precisely asked a question to the participants regarding their behaviors towards Somali Muslims after 
participating in all their select activities: performance(s), (workshop(s), Somali pamphlet review, embedded class assignments, video clip(s), Somali food experience (s), Somali students' night, and shop visit(s); and so forth. The excerpts responses provided by $\mathrm{C} 3$ students to the question: "what misconceptions if any about Muslims/ Somalis did you have that these activities have helped to reduce or erase and how these have changed your behavior towards them?" were used to determine if there were any behavior changes. With regards to misconceptions about Muslims/Somalis the following statements stood out:

"I thought that Somali/Muslims are bad drivers and they do not want to assimilate"

"I thought that some Somali individuals did not like me because I had a big dog and that they were violent and unwilling to assimilate"

I often thought that Muslims keep to themselves and do not like engaging in "typical American" things"

The second potion of the question attempts to find out how the activities that $\mathrm{C} 3$ respondents participated in,changed their behavior towards Muslims/Somalis. The following themes (fun loving and history of trauma) can be derived from the excerpts that $\mathrm{C} 3$ participants provided below:

"There are bad drivers in all ethnic groups and it takes at least 3 generations for people to completely assimilate, so I believe Somalis are going to come around"

"I never knew Somali/Muslims are also fun-loving people"

"I learned a lot about refugee resettlement through this project; since some of them have gone through a lot treating them bad is some kind of double jeopardy"

Another disposition that sheds some more light on the change of future behavior for members of $\mathrm{C} 3$ was rooted in the question: in what ways, if any, did these events reinforce or change the way you think about your community? The responses tended to have the following themes (open attitude and better understanding of Somalis) as captured in the phrases below:

"To better understand others, we have to be able to open up our attitudes and not just assume things about people in our communities"

"Now, I am more comfortable about Somalis living amongst our midst"

"I feel that I better understand how the Somali culture is integrated into the community within which they live"

"I hope the community can be exposed to these kinds of studies"

\section{iv. Cohort Three Knowledge}

To determine the level of understanding of C3 participants on basic views such as knowledge of the Somali peoples and cultures, length of stay in the US, origin \& spirituality, impression of their art and music, exposure to food amongst other things; a 9-question survey was filled at the beginning and at the end of the research. The results of this pre and post survey will be used to show how C3 participants have actually acquired some basic knowledge about Somali Muslims living in central Minnesota. The pre and post charts displayed below show the relative change in knowledge among $\mathrm{C} 3$ respondents before and after the research project.

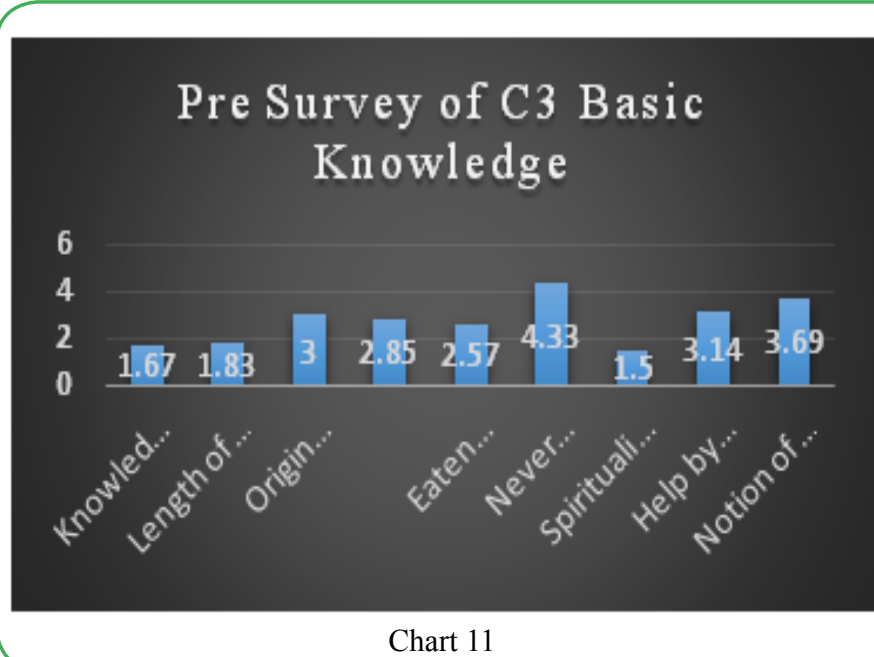

Note that in charts 11 and 12 above, questions in the affirmative have increased scores and questions in the negative have reduced scores in the post survey responses than in the pre-survey responses. These changes are indicative that $\mathrm{C} 3$ participants have gained more about knowledge about Somali peoples and cultures, length of stay in the US, origin \& spirituality, impression of their art and music, exposure to food amongst other things; the research project. See appendix 8 for a full review of the questions asked.

\section{Discussion and Conclusion}

This section highlights certain overarching events that were successful in changing attitudes and increasing interfaith understanding, what made them successful, and the changes/results observed. It also determines if research results confirm or contradict the expectations for particular events that were presented; namely, (activities); and if so, do the participants' responses support these assumptions? (Hard to read sentence).

\section{Areas of success:}

The research was to find out if exposure of participants in $\mathrm{C} 1, \mathrm{C} 2$ and $\mathrm{C} 3$ to certain events would successfully change their attitudes,

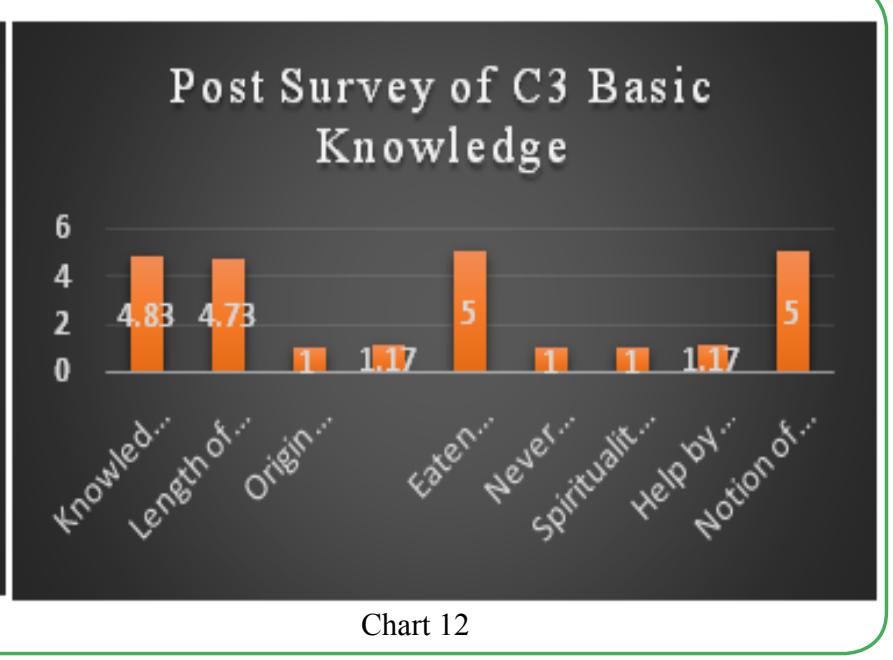

behaviors and increase basic knowledge and understanding of Somali/ Muslims in Minnesota. In discussing if they were changes and what made the changes to be successful, each of these variables, namely, attitude, behavior, and knowledge as analyzed above show that all three cohorts significantly saw positive changes in attitude, behavior and knowledge after the immersion programs. More specifically, given that the changes/results that were actually observed met the goals and objectives of the research project, it seems reasonable to say that Islamic art forms was successful in positively influencing the attitudes, behaviors and knowledge base of millennials across the three cohorts under study.

\section{Lessons on Appropriate Engagement:}

Most of the work done in this research was improvised because the primary artist who was supposed to do the residency at Saint Cloud did not come. Based on this limitation, it became very difficult for the research fellows to learn about respectfully and appropriately engaging Muslim artists and artists from Muslim-majority countries in residency activities. However, certain important things were learned from the interaction with members of the Somali community, 
SSA students, the participation at the Somali night, as well as having Ahmed, Huddah, and Ifrah speak or perform as the case may be. Among the things learned in the area of engaging Muslim artistsis that they should be treated just like any other artist and compensated adequately. It is also important to use consultants from within the group under study. It was only later that the steering committee thought of including the president and vice of SSA and Ahmed as committee members. After the struggle of having the Somali community to turn out for a musical show, it was Ahmed who said that many Somali residents in the area frown at music is because it is considered antiIslam and secular and that contacting the imam and some elders may not be a good idea. This is the knowledge that we stumbled on by chance, whereas with proper engagement and through proper involvement and consultations, we would have had things easier for the committee.

\section{Research Expectations}

To control whether the research results confirm or contradict the expectations for particular events, the researchers selected sesresponses of each activity and this was randomly selected from $\mathrm{C} 1$, $\mathrm{C} 2$, and $\mathrm{C} 3$, and tabulated so that there will be a clear determination of participants' responses in order to support these assumptions. Since the pre and post- surveys have been used elaborately in the subsequent sections of the report, the researchers decided not to include the two activities in this section for analysis.

\begin{tabular}{|c|c|c|}
\hline Event or Program & Participants' Random Responses & Confirm or Contradict \\
\hline Review of MIDNIMO Pamphlet & $\begin{array}{l}\text { "I am happy to read that the musicians that did get } \\
\text { away during the Civil War are finding ways back to } \\
\text { their musical traditions from London, the United States, } \\
\text { Canada, the UK, and across Scandinavia" }\end{array}$ & Confirm \\
\hline Aar Maanta Videos & $\begin{array}{l}\text { "The music video made me think that we are not all that } \\
\text { different, and I hope that people will someday realize } \\
\text { this so the world can change for the better" }\end{array}$ & Confirm \\
\hline Ahmed's Presentation & $\begin{array}{l}\text { "It was sad to learn from Ahmed that when the Civil War } \\
\text { began in } 1991 \text { that many artists and musical groups fled } \\
\text { in fear of their own lives" }\end{array}$ & Confirm \\
\hline Potluck \&Huddah's Presentation & $\begin{array}{l}\text { "I learned from Huddah that it is crucial to learn } \\
\text { about our neighbor's history and culture so there is an } \\
\text { understanding and more overall peace between one } \\
\text { another" overall peace between one another" }\end{array}$ & Confirm \\
\hline Nayiz's Stream & $\begin{array}{l}\text { "I am glad that the Muslim bands like Nayiz's are } \\
\text { becoming an important thing in the United States } \\
\text { because if they are going to live in this country they } \\
\text { should be allowed to enjoy their own traditional music } \\
\text { just like the Americans get to enjoy theirs" }\end{array}$ & Confirm \\
\hline SSA Night & $\begin{array}{l}\text { "This was a culture night that included food, poems, } \\
\text { dances, and songs; but it was so much more than just the } \\
\text { performances. There was a lot of feeling and heart. In } \\
\text { just one night, I got a little taste of what they eat, heard a } \\
\text { little about the issues back in Somalia, and saw some of } \\
\text { the dances that are important to them" }\end{array}$ & Confirm \\
\hline Dr. Lang's Documentary & $\begin{array}{l}\text { "I don't feel that my perception toward Somali/Muslins } \\
\text { has ever been bad, but seeing firsthand the drive and } \\
\text { positive outlook that the individuals in the documentary } \\
\text { had was just another reason that my outlook has } \\
\text { improved yet again" }\end{array}$ & Confirm \\
\hline Visit to a Somali Café or Mall & $\begin{array}{l}\text { "It takes a lot for me to push myself out of my comfort } \\
\text { zone. I am grateful for this assignment because it pushed } \\
\text { me to experience something new and to learn about } \\
\text { another culture. Once inside the café I felt intrigued to } \\
\text { try the Sambusa is a triangular pastry usually filled with } \\
\text { either ground beef or lamb. I was told it went well with } \\
\text { Somali tea and Mushakal smoothies. I was glad that I } \\
\text { tried it because overall, I had a positive experience" }\end{array}$ & Confirm \\
\hline Ifrah's Poetry Presentation & $\begin{array}{l}\text { "Listening to Ifrah's story about their experiences and } \\
\text { survival of the civil war really opened my eyes to why } \\
\text { people should be more open minded about Somali } \\
\text { refugees and not do anything to victimize them yet } \\
\text { again" }\end{array}$ & Confirm \\
\hline
\end{tabular}

Table 1

The research results as depicted in these excerpts that have randomly selected tie with the expectations or objectives of the project. Each of the excerpts confirm that the attitudes of the participants indeed changed after exposure to the activities and programs that they as seen in the table. Quantitative and qualitative data in this evaluation therefore support changes in students' opinions which is indicative these results were void of any flawed research methods, a faulty hypothesis or any unrealistic expectations. Thus, the program really 
had much of an effect on the participants.

\section{Areas of improvement}

There are some areas where improvement can be done particularly if other campuses plan similar initiatives in the future. First, it is necessary to revisit the notion of sustainability. While it is lofty to have locals pay for the musical shows of residents, note show be taken that attending musical shows is not a thing for many Somalis who are either not well to do or because of religious reasons would not want to attend such shows. In this regard, these shows should be done in public places like at Lake George at no cost and not at the Paramount. Second, it is of critical importance to paying attention to cultural competence. Members of the steering committee should not just be a group of Caucasian men just because they are part of the music and performing Art Department; they should actually be trained on diversity, or the group should include persons from the community that is being solicited, or at least a consultant who knows and has worked with this community should be recruited. Third, making sure that those who are recruited for the research are properly incentivized with gift cards; this is the most single reason why in spite of the inconsistencies and sudden changes in the schedules, 22 out of the 24 participants still managed to complete the research. Fourth, given that $\mathrm{C} 1, \mathrm{C} 2$, and $\mathrm{C} 3$ participants consistently stated that they enjoyed the food, it would be a good thing to consider arranging events that would have a food tasting component at them. After all, there is an African proverb that "if you want to reach my heart, you pass through the mouth." Maybe alongside food; people just like the millennials in this study would better appreciate Somali/Muslim music, art and culture; and by extension learn to coexist within the same geographic spaces.

Conflict of interest: The authors have declared no conflict of interest.

\section{References}

1. Davis, K.C. (2010). America's True History of Religious Tolerance: Smithsonian Magazine:

2. Koppelman, K. L. (2014). Understanding Human Difference: Multicultural Education for a Diverse America. Pearson, Upper Saddle River, NJ.

3. Allen, C. (2012). Islamophobia and anti-Muslim hatred: influencing policy at the government level:

4. Du, S. (2016). St. Cloud is the Worst Place in Minnesota To Be Somali:

5. Lamin S.A., and Teboh, C (2016). Police Social Work and Community Policing. Law, Criminology \& Criminal Justice Research Article. Cogent Social Sciences, 2: 1212636

6. Perry, B. (2001). In the Name of Hate: Understanding Hate Crimes: Routledge. New York, NY 10001.

7. Pew Research Center, (2012). Rising Tide of Restrictions on Religion.

8. Mullen, M. (2016). Rochester Cop on Leave for Sharing Stupid, Racist Memes on Facebook:

9. Rucke, K. (2014). Civil Rights Groups Protest Closures of Muslims' Bank Accounts:

10. ACLU, Minnesota, (2017). ACLU-MN v. U.S. Department of Homeland Security and U.S. Customs and Border Protection Retrieved on July 6, 2018

11. City of Minneapolis Ordinance 389.05. (2013). Authority to prevent noise, Ch. 4, §5(3).

12. Firestone, R.R (2010). Islamophobia \& Anti-Semitism: History andPossibility. Arches Quarterly, volume 4 edition 7 winter 2010.

13. Allen, C. (2007). Islamophobia and its Consequences: Centre for European Policy Studies (CEPS):
14. IslamiCity (2010). Racial Profiling Will Aggravate Terror Mindset. September 14, 2018

15. Loonwatch, (2011). All Terrorists are Muslim...Except the $94 \%$ that Aren't. September 14, 2018

16. Walters, A. M. (2010). A General Theories of Hate Crime? Strain, Doing Difference and Self Control: Critical Criminology DOI 10.1007/s10612-010-9128-

17. University of California-Berkeley, (2015). Center for Race and Gender: Islamophobia. September 14, 2018

18. Pappas, S (2012). Negative Portrayals of Muslims Get More Media Attention. Human Nature. Retrieved on March 12, 2019

19. Muslim Youth Foundation (2017). Building Bridges with the Community: Why Is Islam Misunderstood? Retrieved on March 12,2019

20. Woofe, S. (2018). The Role of the Media in the Spread of Islamophobia. Retrieved on March 12, 2019

21. Yilmaz, I. (2011). 'Beyond Post-Islamism: Transformation of Turkish Islamism Toward "Civil Islam" and Its Potential Influence in the Muslim World', European Journal of Economic and Political Studies, 4, 1. 